\title{
Carnosic acid-rich rosemary (Rosmarinus officinalis L.) leaf extract limits weight gain and improves cholesterol levels and glycaemia in mice on a high-fat diet
}

\author{
Alvin Ibarra $^{1 *}$, Julien Cases ${ }^{2}$, Marc Roller $^{2}$, Amparo Chiralt-Boix ${ }^{3}$, Aurélie Coussaert ${ }^{4}$ \\ and Christophe Ripoll ${ }^{4}$ \\ ${ }^{1}$ Naturex, Inc., 375 Huyler Street, South Hackensack, NJ 07606, USA \\ ${ }^{2}$ Naturex SA, Site d'Agroparc BP 1218, 84911 Avignon Cedex 9, France \\ ${ }^{3}$ Universidad Politécnica de Valencia, Departamento de Tecnología de los Alimentos, Camino de Vera s/n, Valencia, Spain \\ ${ }^{4}$ Naturalpha SAS, Parc Eurasanté, Lille Métropole 85, Rue Nelson Mandela, 59120 Loos, France
}

(Received 10 August 2010 - Revised 16 February 2011 - Accepted 27 February 2011)

\section{Abstract}

Rosemary (Rosmarinus officinalis L.) extracts (RE) are natural antioxidants that are used in food, food supplements and cosmetic applications; exert anti-inflammatory and anti-hyperglycaemic effects; and promote weight loss, which can be exploited to develop new preventive strategies against metabolic disorders. Therefore, the aim of the present study was to evaluate the preventive effects of rosemary leaf extract that was standardised to $20 \%$ carnosic acid (RE) on weight gain, glucose levels and lipid homeostasis in mice that had begun a high-fat diet (HFD) as juveniles. The animals were given a low-fat diet, a HFD or a HFD that was supplemented with 500 mg RE/kg body weight per $\mathrm{d}(\mathrm{mpk})$. Physiological and biochemical parameters were monitored for 16 weeks. Body and epididymal fat weight in animals on the HFD that was supplemented with RE increased 69 and $79 \%$ less than those in the HFD group. Treatment with RE was associated with increased faecal fat excretion but not with decreased food intake. The extract also reduced fasting glycaemia and plasma cholesterol levels. In addition, we evaluated the inhibitory effects of RE in vitro on pancreatic lipase and PPAR- $\gamma$ agonist activity; the in vitro findings correlated with our observations in the animal experiments. Thus, the present results suggest that RE that is rich in carnosic acid can be used as a preventive treatment against metabolic disorders, which merits further examination at physiological doses in randomised controlled trials.

Key words: Rosmarinus officinalis L.: Carnosic acid: Pancreatic lipase: PPAR- $\gamma$

The prevalence of metabolic disorders, such as obesity, hyperlipidaemia and hyperglycaemia, is rising dramatically in developing and industrialised nations. Obesity is reaching epidemic proportions worldwide ${ }^{(1)}$ and is an established risk factor for various comorbidities, such as type 2 diabetes mellitus and $\mathrm{CVD}^{(2-4)}$. The development of obesity induces systemic oxidative stress $^{(5)}$ and affects the inflammatory state $^{(6)}$. The constant increase in fat intake that is linked with sedentary lifestyles is the chief cause of this phenomenon $^{(2)}$.

Developing preventive and therapeutic solutions that impede the rise in metabolic disorders has become a primary goal in the past decade. In addition to pharmaceutical approaches, the use of natural products in physiological doses has been recognised as an effective regimen to improve several health conditions ${ }^{(7-9)}$. Plant-based treatments have been validated as strategies in the prevention of obesity and type 2 diabetes mellitus ${ }^{(10)}$.

Rosemary (Rosmarinus officinalis L.) extracts are natural antioxidants that are used in food, food supplements and cosmetic applications ${ }^{(11-15)}$. Recently, rosemary extracts that have been standardised for carnosic acid and carnosol attained antioxidant status, garnering an additive E classification from the European Food Safety Authority, confirming its importance as a natural preservative in foods and beverages ${ }^{(13)}$.

Carnosic acid-rich rosemary extract has been reported to have antioxidant activity in vitro by oxygen radical absorbance capacity and ferric-reducing/antioxidant power assays, and it inhibits the oxidation of $\mathrm{Cu}^{2+}$-induced LDL ex vivo ${ }^{(15)}$. These antioxidant effects have been recapitulated in vivo. Consequently, carnosic acid-rich rosemary extract reduces oxidative stress in aged rats ${ }^{(16)}$. Carnosic acid has

Abbreviations: HFD, high-fat diet; LFD, low-fat diet; mpk, mg rosemary extract/kg body weight per d; RE, rosemary extract.

*Corresponding author: Dr A. Ibarra, fax +1 201342 8000, email a.ibarra@naturex.us 
anti-inflammatory effects in cellular ${ }^{(17)}$ and animal ${ }^{(18)}$ models. Furthermore, carnosic acid has promising anti-obesity and anti-glycaemic effects.

In in vitro trials, carnosic acid inhibits pancreatic lipase ${ }^{(19)}$, activates PPAR- $\gamma^{(20)}$ and prevents the differentiation of mouse pre-adipocytes into adipocytes ${ }^{(21)}$ - all of which are important mechanisms in glucose and lipid homeostasis. The capacity of rosemary to regulate weight gain ${ }^{(22,23)}$ and glycaemia ${ }^{(22-24)}$ has been observed in vivo. Nevertheless, no randomised clinical trials have been reported using rosemary extracts to control obesity and hyperglycaemia, but this evidence encourages further study of carnosic acid-rich rosemary extracts to prevent the development of metabolic disorders.

In the present study, we aimed to determine the preventive effects of a rosemary extract that was standardised to contain $20 \%$ carnosic acid (RE) on weight gain, glycaemia levels and lipid homeostasis in mice that were started on a high-fat diet (HFD) as juveniles. The animals were given a low-fat diet (LFD), a HFD or a HFD with $500 \mathrm{mg}$ RE/kg body weight per d (mpk) (HFD-RE). Physiological and biochemical parameters were measured throughout the 16 weeks of treatment, and the effects on pancreatic lipase and PPAR- $\gamma$ agonist activity in vitro were examined.

\section{Experimental methods}

\section{Rosemary leaf extract}

RE was prepared as described by Ibarra et al. ${ }^{(15)}$.

\section{Animals and diet}

Male C57BL/6J mice, aged 4 weeks, were purchased from Elevage Janvier (CERJ, Le Genest Saint Isle, France). All mice were housed in a cage on a $12 \mathrm{~h}$ light $-12 \mathrm{~h}$ dark cycle in a temperature-controlled environment during a 2-week acclimatisation, with ad libitum access to water and a control standard diet - an energy-balanced diet. After acclimatisation, the mice were randomised by body weight into three groups of eight animals. Each group was fed an experimental diet (Research Diets, Inc., New Brunswick, NJ, USA) for 16 weeks, as described in Table 1 (LFD, HFD and HFD-RE). Body weight was measured twice per week, and food intake was recorded once per week. All procedures were performed as per French guidelines for the care and use of experimental animals.

\section{Blood biochemistry}

Blood was collected from the retro-orbital sinus into EDTAcoated tubes under isoflurane anaesthesia after overnight fasting. Samples were collected at the beginning of the study (day 0) and after 16 weeks on the experimental diets. Blood samples were centrifuged at $4000 \mathrm{rpm}$ for $15 \mathrm{~min}$ at $4^{\circ} \mathrm{C}$ to recover the plasma.

Biochemical levels were measured using commercial kits. Total cholesterol, TAG, glucose (kits CH3810, TR3823 and GL3815; Randox Laboratories Limited, Newbury, Berkshire, UK) and NEFA (kit 434-91717; Wako Pure Chemical Industries
Limited, Osaka, Japan) were measured by spectroscopy. Insulin (kit INSKR020; Crystal Chem, Inc., Downers Grove, IL, USA) was measured by ELISA.

\section{Faecal lipid measurements}

Faeces were collected at weeks 0,8 and 16 , frozen at $-80^{\circ} \mathrm{C}$ and pulverised. For each condition, faeces from eight mice, harvested during a $24 \mathrm{~h}$ period, were pooled. Total lipids were extracted from $100 \mathrm{mg}$ of dried faeces as described ${ }^{(25)}$. Total lipid levels from several independent extractions were estimated by traditional gravimetric analysis: $500 \mu \mathrm{l}$ of total lipids in chloroform were dried by evaporation and weighed.

The amount of faecal fat energy that was excreted, expressed in $\mathrm{kJ} /$ animal per $\mathrm{d}$, was calculated in the lyophilised total fat that was excreted and collected throughout the experiment, assuming that $1 \mathrm{~g}$ lipid equals $37 \cdot 7 \mathrm{~kJ}$.

\section{Pancreatic lipase activity assay}

Human pancreatic lipase was purchased from Lee Biosolutions, Inc. (St Louis, MO, USA). Orlistat (tetrahydrolipstatin, a pancreatic lipase inhibitor) was purchased from Sigma Chemical Company (St Louis, MO, USA). Other chemicals were of reagent grade. The pancreatic lipase was diluted in dimethyl sulfoxide to obtain a final activity of $0 \cdot 1 \times 10^{6} \mathrm{U} / \mathrm{l}$. Orlistat was tested at two concentrations in dimethyl sulfoxide.

Lipase activity was measured using the ENZYLINETM Lipase Colour Assay kit (Biomérieux, Marcy-l'Etoile, France) according to the manufacturer's instructions. Briefly, pancreatic lipase, substrate and the test sample were mixed gently, and incubated for $5 \mathrm{~min}$ at $37^{\circ} \mathrm{C}$. Activator reagent was added, and the mixtures were incubated again for $6 \mathrm{~min}$ at $37^{\circ} \mathrm{C}$. The recorded rate of increase in absorbance at $550 \mathrm{~nm}$, due to the formation of quinone diimine dye, reflected pancreatic lipase activity.

\section{PPAR- $\gamma$ assay}

PPAR- $\gamma$ activation was measured in a cell-based luciferase assay. COS-7 cells (African Green Monkey SV40-transformed kidney fibroblast cell line), cultured in Dulbecco's modified Eagle's medium that was supplemented with $10 \%$ fetal calf serum, were transiently transfected with a fusion protein GAL4/PPAR$\gamma$ and a DNA construct that harboured the gene reporter. The plasmid pGal5-TK-pGL3 was obtained by inserting five copies of the Gal4 (a yeast transcription factor) DNA-binding site upstream of the thymidine kinase promoter in pTK-pGL3.

The plasmid pGal4-human PPAR- $\gamma$ was constructed by PCR amplification of the human PPAR- $\gamma$ DEF domain (nuclear receptor Hinge region (D) + ligand binding domain (E) + C-terminal domain (F)) (aa 318-505). The resulting amplicons were cloned into pBD-Gal4 (Stratagene, La Jolla, CA, USA), and the chimera was subsequently subcloned into pCDNA3.

After transfection, the COS-7 cells were incubated for $24 \mathrm{~h}$ with RE to assess its capacity to activate PPAR- $\boldsymbol{\gamma}$. Dimethyl sulfoxide was used as the reference control, and rosiglitazone was used as a positive control. The activation of PPAR- $\gamma$ by RE 
Table 1. Composition of the experimental low-fat diet (LFD), high-fat diet (HFD) or a HFD plus rosemary extract (RE) and macronutrient content (\%)

\begin{tabular}{|c|c|c|c|c|c|c|c|c|c|c|c|c|}
\hline & \multicolumn{4}{|c|}{ HFD } & \multicolumn{4}{|c|}{ LFD } & \multicolumn{4}{|c|}{ HFD-RE $0.5 \%$ (500 mpk) } \\
\hline & g & $\mathrm{kJ}$ & $\mathrm{g} / \mathrm{kg}$ & $\mathrm{kJ} / \mathrm{kg}$ & g & $\mathrm{kJ}$ & $\mathrm{g} / \mathrm{kg}$ & $\mathrm{kJ} / \mathrm{kg}$ & g & $\mathrm{kJ}$ & $\mathrm{g} / \mathrm{kg}$ & $\mathrm{kJ} / \mathrm{kg}$ \\
\hline Compound & & & & & & & & & $4 \cdot 31$ & 0 & 5.00 & 0 \\
\hline Casein 80 mesh & 200 & $3349 \cdot 4$ & 233 & $3902 \cdot 1$ & 200 & 3349.4 & 190 & $3173 \cdot 6$ & 200 & 3349.4 & 231.89 & $3902 \cdot 1$ \\
\hline L-Cysteine & 3 & $50 \cdot 2$ & 3 & $58 \cdot 6$ & 3 & $50 \cdot 2$ & 3 & $46 \cdot 1$ & 3 & $50 \cdot 2$ & 3.48 & 58.6 \\
\hline Maize starch & $72 \cdot 8$ & $1219 \cdot 2$ & 85 & $1419 \cdot 3$ & 315 & 5275.4 & 299 & $4999 \cdot 0$ & $72 \cdot 8$ & $1219 \cdot 2$ & 84.41 & 1419.3 \\
\hline Maltodextrin 10 & 100 & $1674 \cdot 7$ & 117 & $1951 \cdot 0$ & 35 & $586 \cdot 2$ & 33 & $556 \cdot 8$ & 100 & $1674 \cdot 7$ & $115 \cdot 95$ & $1951 \cdot 0$ \\
\hline Sucrose & $172 \cdot 8$ & 2893.9 & 201 & $3370 \cdot 4$ & 350 & 5861.5 & 332 & 5555.9 & $172 \cdot 8$ & 2893.9 & $200 \cdot 36$ & 3370.4 \\
\hline Cellulose BW200 & 50 & 0 & 58 & 0 & 50 & 0 & 47 & 0 & 50 & 0 & 57.97 & 0 \\
\hline Soyabean oil & 25 & $942 \cdot 0$ & 29 & $1096 \cdot 9$ & 25 & $942 \cdot 0$ & 24 & 891.8 & 25 & $942 \cdot 0$ & 28.99 & 1096.9 \\
\hline Lard & 177.5 & $6688 \cdot 4$ & 207 & $7795 \cdot 8$ & 20 & $753 \cdot 6$ & 19 & $715 \cdot 9$ & 177.5 & $6688 \cdot 4$ & $205 \cdot 81$ & 7795.8 \\
\hline Mineral mix & 10 & 0 & 12 & 0 & 10 & 0 & 9 & 0 & 10 & 0 & 11.59 & 0 \\
\hline Calcium phosphate & 13 & 0 & 15 & 0 & 13 & 0 & 12 & 0 & 13 & 0 & $15 \cdot 07$ & 0 \\
\hline Calcium carbonate & 5.5 & 0 & 6 & 0 & 5.5 & 0 & 5 & 0 & 5.5 & 0 & 6.38 & 0 \\
\hline Potassium citrate & $16 \cdot 5$ & 0 & 19 & 0 & $16 \cdot 5$ & 0 & 16 & 0 & $16 \cdot 5$ & 0 & $19 \cdot 13$ & 0 \\
\hline Vitamin mix & 10 & $167 \cdot 5$ & 12 & $196 \cdot 8$ & 10 & $167 \cdot 5$ & 9 & $159 \cdot 1$ & 10 & $167 \cdot 5$ & 11.59 & $196 \cdot 8$ \\
\hline Choline bitartrate & 2 & 0 & 2 & 0 & 2 & 0 & 2 & 0 & 2 & 0 & $2 \cdot 32$ & 0 \\
\hline Dye & 0.05 & 0 & 0 & 0 & 0.05 & 0 & 0 & 0 & 0.05 & 0 & 0.06 & 0 \\
\hline Total & $858 \cdot 2$ & $16985 \cdot 4$ & $1000 \cdot 0$ & $19791 \cdot 0$ & $1055 \cdot 1$ & $16985 \cdot 8$ & $1000 \cdot 0$ & $16098 \cdot 2$ & $862 \cdot 5$ & $16985 \cdot 4$ & $1000 \cdot 0$ & $19791 \cdot 0$ \\
\hline Protein (\%) & $23 \cdot 66$ & 20.02 & & & $19 \cdot 24$ & 20.01 & & & $23 \cdot 66$ & $20 \cdot 02$ & & \\
\hline Carbohydrate (\%) & $40 \cdot 27$ & 34.08 & & & $66 \cdot 35$ & $69 \cdot 02$ & & & $40 \cdot 27$ & 34.08 & & \\
\hline Fat $(\%)$ & $23 \cdot 60$ & 44.92 & & & $4 \cdot 27$ & 9.98 & & & $23 \cdot 60$ & 44.92 & & \\
\hline
\end{tabular}

$\mathrm{mpk}$, mg rosemary extract/kg body weight per $\mathrm{d}$. 


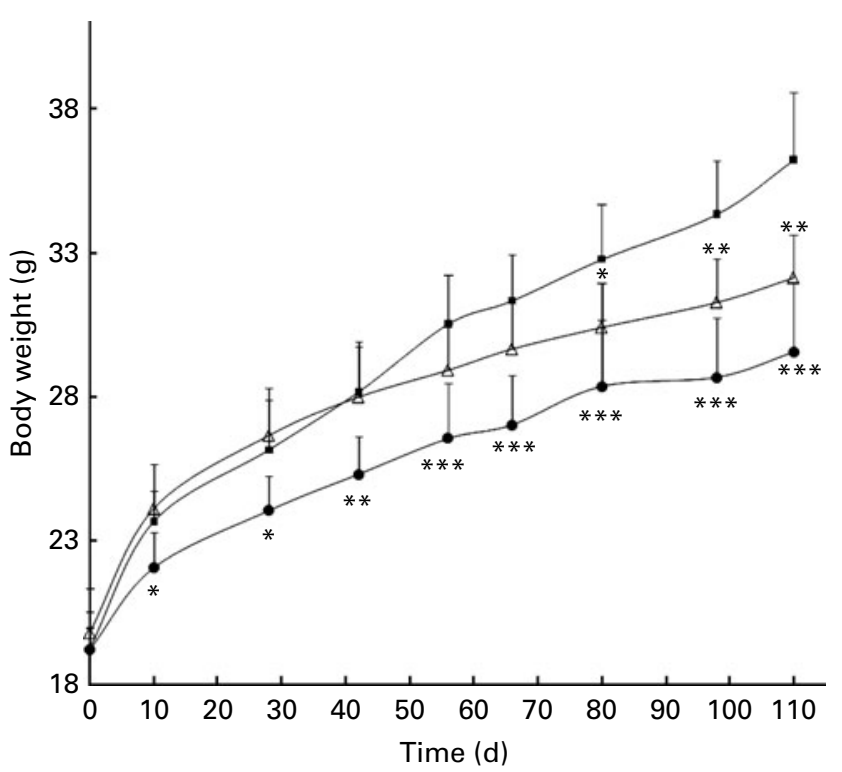

Fig. 1. Effects of rosemary extract (RE) standardised to $20 \%$ carnosic acid on body weight after 16 weeks. Low-fat diet ( $\square$ ), high-fat diet (HFD, $\square$ ) and HFD supplemented with RE (HFD-RE, $\square$ ) at a concentration equivalent to $500 \mathrm{mg} \mathrm{RE} / \mathrm{kg}$ body weight per d. Values are means, with standard deviations represented by vertical bars. Mean values were significantly different from HFD control (ANOVA one-way Bonferroni): ${ }^{*} P<0.05$, ${ }^{\star *} P<0.01$, ${ }^{\star \star \star} P<0.001$.

induced the expression of luciferase and a consequent increase in luminescence.

After $24 \mathrm{~h}$, the cells were collected, and the luciferase assay was performed according to the manufacturer's instructions (SteadyGlow; Promega, Charbonnières, France). Luminescence was measured on a Tecan Ultra spectrophotometer (Tecan, Männedorf, Switzerland). All experiments were performed in quadruplicate. Relative luciferase activity of a sample was calculated as the ratio of mean luciferase activity in the test cells to that in the control cells, and PPAR- $\gamma$ ligand-binding activity was expressed as the ratio of relative luciferase activity to that of the reference control.

\section{Analysis of results}

The animals were randomised based on total body weight by principal component analysis (GENFIT, Loos, France), resulting in groups of animals between which no statistical difference was observed for any parameter.
The data from the in vivo and in vitro studies are expressed as means and standard deviations. One-way ANOVA (one-way Bonferroni) and Student's $t$ test were performed to compare groups using Sigma Plot 11.0 (2008) (Systat Software, Inc., Chicago, IL, USA). Statistical significance was considered at $P<0.05$.

In the in vivo study, gains in the HFD-RE group are expressed as a percentage compared with those in the HFD and LFD control groups, which is calculated as:

$$
\text { Parameter }(\%)=((\mathrm{HFD}-\mathrm{HFD}-\mathrm{RE}) /(\mathrm{HFD}-\mathrm{LFD})) \times 100 .
$$

In the in vitro studies, changes are expressed relative to their respective controls.

\section{Results}

Effect of rosemary extract on body and organ weight and food intake in mice fed a high-fat diet

Body weight between the HFD and LFD groups began to differ significantly after the first week of treatment. In HFD$\mathrm{RE}$ animals, body weight differed significantly after day 80 (Fig. 1) compared with that in HFD mice and weight gain peaked at $69 \%(P<0.01)$ at the end of the study (Table 2$)$. This effect was associated with a $79 \%(P<0.001)$ less of an increase in epididymal fat mass; liver weight was unaffected by the treatment. No significant changes in food or energy intake were observed between the groups (Table 2).

\section{Effects of rosemary extract on serum biochemical parameters}

At 16 weeks of treatment, total fasting glycaemia, total cholesterol and NEFA levels rose significantly in the HFD group compared with the LFD animals. HFD-RE mice experienced $72 \%$ $(P<0.01)$ less increase in plasma glucose levels and $68 \%$ $(P<0.001)$ less an a rise in total cholesterol compared with HFD mice. No significant effects were observed in NEFA or TAG levels in HFD-RE mice compared with the HFD group (Table 3).

Fasting insulinaemia was also monitored; insulin levels remained low during the entire experiment, and no significant differences were observed between the groups (data not shown).

Table 2. Effects of chronic administration of rosemary extract (RE) standardised to $20 \%$ carnosic acid on nutritional and weight parameters in mice fed a low-fat diet (LFD), a high-fat diet (HFD) or a HFD plus RE after 16 weeks (Mean values and standard deviations)

\begin{tabular}{|c|c|c|c|c|c|c|c|c|c|c|}
\hline \multirow[b]{2}{*}{ Animal group } & \multicolumn{2}{|c|}{$\begin{array}{l}\text { Food intake } \\
\text { (g/animal per d) }\end{array}$} & \multicolumn{2}{|c|}{$\begin{array}{l}\text { Energy intake } \\
\text { (kJ/animal per d) }\end{array}$} & \multicolumn{2}{|c|}{ Weight gain (g) } & \multicolumn{2}{|c|}{ Liver weight (g) } & \multicolumn{2}{|c|}{$\begin{array}{l}\text { Epididymal fat } \\
\text { weight }(\mathrm{g})\end{array}$} \\
\hline & Mean & SD & Mean & SD & Mean & SD & Mean & SD & Mean & SD \\
\hline LFD & 3.40 & 0.28 & $61 \cdot 7$ & 5.3 & $10 \cdot 33^{\star \star \star}$ & $2 \cdot 18$ & 0.99 & $0 \cdot 10$ & $0.45^{\star \star \star}$ & 0.26 \\
\hline HFD & 3.09 & 0.19 & 67.5 & $2 \cdot 2$ & $17 \cdot 01$ & 1.94 & $1 \cdot 12$ & 0.13 & 1.52 & 0.48 \\
\hline HFD-RE & 3.01 & $0 \cdot 10$ & $62 \cdot 8$ & 1.3 & $12 \cdot 37^{\star \star}$ & 1.59 & $1 \cdot 14$ & 0.15 & $0.67^{\star \star \star}$ & 0.15 \\
\hline
\end{tabular}

Mean values were significantly different from HFD control (ANOVA one-way Bonferroni): ${ }^{\star \star} P<0.01$ and ${ }^{\star \star \star} P<0.001$. 
Table 3. Effects of chronic administration of rosemary extract (RE) standardised to $20 \%$ carnosic acid on plasma lipid and glucose levels in mice fed a low-fat diet (LFD), a high-fat diet (HFD) or a HFD plus RE after 16 weeks

(Mean values and standard deviations)

\begin{tabular}{|c|c|c|c|c|c|c|c|c|}
\hline \multirow[b]{2}{*}{ Animal group } & \multicolumn{2}{|c|}{$\begin{array}{l}\text { Total cholesterol } \\
(\mathrm{mg} / \mathrm{l})\end{array}$} & \multicolumn{2}{|c|}{ TAG (mg/l) } & \multicolumn{2}{|c|}{$\begin{array}{c}\text { NEFA } \\
(\mathrm{mmol} / \mathrm{l})\end{array}$} & \multicolumn{2}{|c|}{ Glucose (mg/l) } \\
\hline & Mean & SD & Mean & SD & Mean & SD & Mean & SD \\
\hline LFD & $1076 \cdot 6^{* \star \star}$ & 48 & $891.4^{*}$ & 125.9 & 1.46 & $2 \cdot 2$ & $1286^{\star \star \star}$ & 182.5 \\
\hline HFD & $1475 \cdot 8$ & $136 \cdot 3$ & 1297.3 & 374.6 & 1.45 & $1 \cdot 1$ & 1978.1 & 492.6 \\
\hline HFD-RE & $1205^{\star \star *}$ & 154.6 & $1021 \cdot 1$ & $256 \cdot 8$ & 1.47 & $2 \cdot 8$ & $1480^{\star \star}$ & $113 \cdot 3$ \\
\hline
\end{tabular}

Mean values were significantly different from HFD control (ANOVA one-way Bonferroni): ${ }^{*} P<0.05,{ }^{\star \star} P<0.01$ and ${ }^{\star \star \star} P<0.001$.

\section{Effect of rosemary extract on faecal fat excretion}

HFD animals had higher faecal fat excretion values (7.63 (SD 1.27$) \mathrm{mg} / 100 \mathrm{mg}$ ) compared with LFD mice (2.74 (SD $0 \cdot 10) \mathrm{mg} / 100 \mathrm{mg}, P<0 \cdot 001)$ after 16 weeks. Moreover, REtreated mice experienced a significant $1 \cdot 2$-fold increase $(P<0 \cdot 01)$ in total faecal content compared with HFD animals (Fig. 2).

Throughout the experiment, there was no significant difference in fat energy intake between the HFD and HFD-RE groups. However, faecal fat energy excretion rose 1.3-fold $(P<0.05)$ in RE-treated mice $(1.13(\mathrm{SD} 0.16) \mathrm{kJ} /$ animal per $\mathrm{d})$ $v$. the HFD group $(0.87(\mathrm{SD} 0.15) \mathrm{kJ} /$ animal per $\mathrm{d})$. Faecal fat energy excretion differed between the LFD group ( 0.32 (SD $0 \cdot 01) \mathrm{kJ} /$ animal per $\mathrm{d}, P<0 \cdot 001)$ and HFD mice (Fig. 3).

\section{In vitro analysis of the mechanism of rosemary extract}

As shown in Fig. 4, $100 \mu \mathrm{g} / \mathrm{ml} \mathrm{RE}(P<0.001)$ inhibited pancreatic lipase activity by $70 \%$ compared with Orlistat. RE also activated PPAR- $\gamma$ by 1.66 -fold $(P<0.001)$ in a dosedependent manner compared with the blank control at $30 \mu \mathrm{g} / \mathrm{ml}$ (Fig. 5), whereas activation in the positive control, rosiglitazone, was 4.35 -fold $(P<0 \cdot 001)$ that in the blank

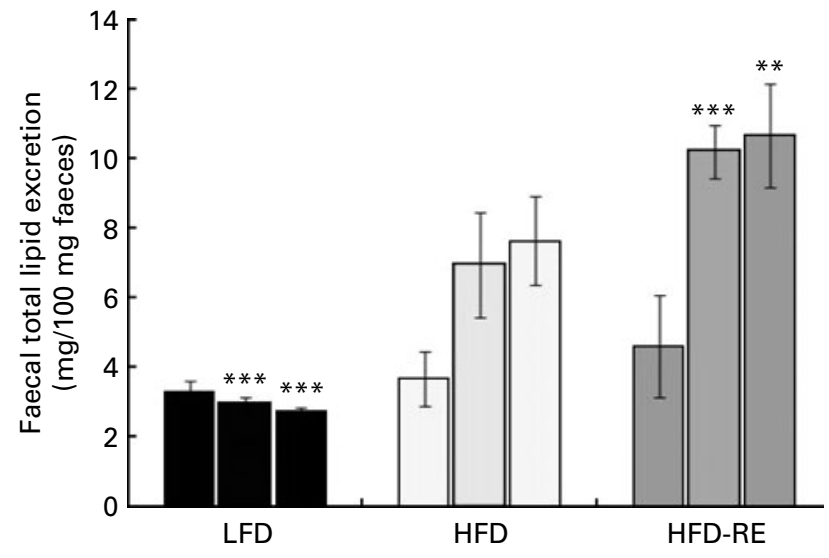

Fig. 2. Effects of rosemary extract (RE) standardised to $20 \%$ carnosic acid on total faecal lipid content at weeks 0,8 and 16. Low-fat diet (LFD), high-fat diet (HFD) and HFD supplemented with RE (HFD-RE) at a concentration equivalent to $500 \mathrm{mg} \mathrm{RE} / \mathrm{kg}$ body weight per $\mathrm{d}$. Values are means, with standard deviations represented by vertical bars of pooled data ( $n 6$; except for LFD, $n 3$ ). Mean values were significantly different from HFD control (ANOVA one-way Bonferroni): ${ }^{* \star} P<0.01$, ${ }^{\star * \star} P<0.001$. control at $10 \mathrm{~nm}$. Therefore, $30 \mu \mathrm{g} / \mathrm{ml}$ RE are able to activate PPAR- $\boldsymbol{\gamma}$ by $19 \cdot 70 \%$ compared with the positive control.

\section{Discussion}

The production of $\mathrm{RE}$, estimated to exceed 100 tonnes annually, has risen considerably in recent years due to its widespread use in food, beverage, flavour, food supplements and cosmetic applications ${ }^{(11-15)}$. Consequently, technologies to develop standardised extracts from rosemary have evolved tremendously with regard to quality and reproducibility. Recently, we have demonstrated the importance of standardisation in determining the biological activity of plant extracts. Furthermore, depending on the content, we have observed that the antioxidant activities of various preparations of RE vary ${ }^{(15)}$.

Rosemary exerts various biological activities with which preventive nutritional strategies against metabolic disorders, such as obesity, dyslipidaemia and diabetes, can be developed ${ }^{(19-23)}$. Nevertheless, individual studies have examined specific extracts, the chemical description of which is not always available. Thus, it can be difficult to extrapolate the health benefits of a unique RE to another solely on the basis of published data.

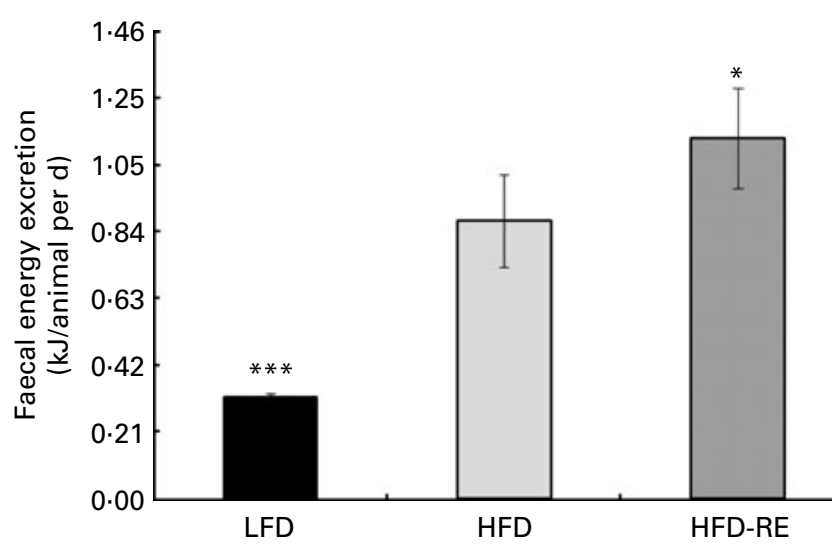

Fig. 3. Effects of rosemary extract (RE) standardised to $20 \%$ carnosic acid on total faecal energy excretion over 16 weeks. Low-fat diet (LFD), high-fat diet (HFD) and HFD supplemented with RE (HFD-RE) at a concentration equivalent to $500 \mathrm{mg} \mathrm{RE} / \mathrm{kg}$ body weight per $\mathrm{d}$. Values are means, with standard deviations represented by vertical bars of pooled data ( $n$ 6; except for LFD, $n 3$ ). Mean values were significantly different from HFD control (Student's $t$ test): * $P<0.05,{ }^{* \star *} P<0.001$. 


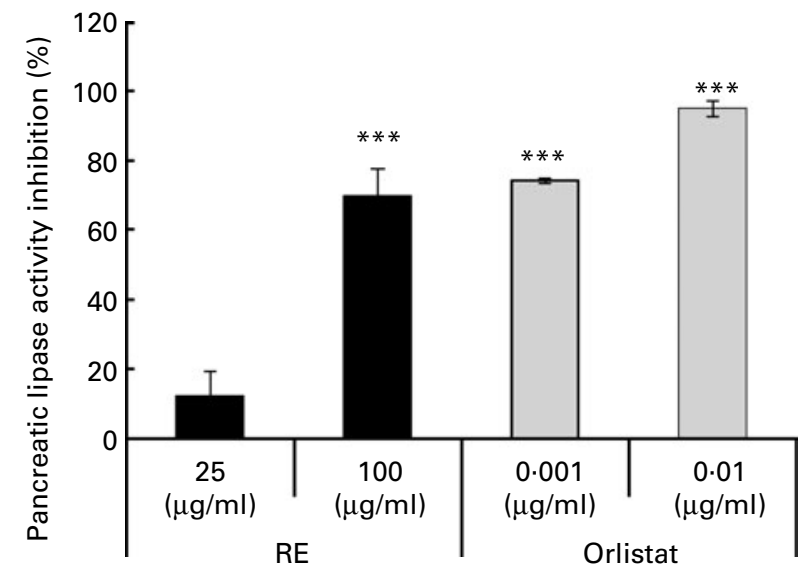

Fig. 4. Effects of rosemary extract (RE) standardised to $20 \%$ carnosic acid on pancreatic lipase inhibition in vitro. Values are means, with standard deviations represented by vertical bars expressed as a percentage of inhibition of three independent experiments. Mean values were significantly different from the blank control (Student's $t$ test): ${ }^{\star \star \star} P<0.001$.

In a previous study, we identified $\mathrm{RE}$ as the most potent antioxidative extract in an ex vivo LDL oxidation model ${ }^{(15)}$, prompting us to determine whether it affects other metabolic parameters in a HFD mouse model. In the present study, the administration of a $44.92 \%$ fat diet to 6-week-old C57BL/6J mice for 16 weeks resulted in significant increases in body weight, epididymal fat mass, glycaemia and cholesterol, compared with a LFD, confirming previous reports ${ }^{(26,27)}$.

Treatment of mice with $500 \mathrm{mpk}$ of RE reduced the gains in weight that were induced by the HFD without affecting food intake or fat energy intake. It also lowered epididymal fat tissue weight significantly compared with HFD mice. In addition, total faecal lipid content increased in HFD-RE mice compared with the HFD group, which correlates with the amount of total faecal fat energy that was excreted. Based on the present study and other reports ${ }^{(19,22)}$, limiting lipid absorption in the intestine is a potential mechanism by which RE prevents weight gain.
This hypothesis is strongly supported by evidence of the in vitro inhibitory effect of RE on pancreatic lipase activity, a key enzyme in the digestion and absorption of fat. Moreover, similar effects have recently been reported with an ethanolic extract of rosemary that contains rosmarinic acid, carnosol and carnosic acid, wherein the treatment of 15-week-old diet-induced obesity mice with $200 \mathrm{mpk}$ of extract limited the weight gain that was induced by a $50 \mathrm{~d}$ HFD and increased the lipid faecal content by $2 \cdot 2$-fold. Ninomiya et al. ${ }^{(19)}$ observed that after 2 weeks of treatment with $20 \mathrm{mpk}$ of carnosic acid alone, the weight of ddY (Deutschland, Derker, Yoker) mice fell by $7 \cdot 6 \%$ compared with the control group. Thus, in the present study, the effects of $\mathrm{RE}$ on faecal fat excretion and, consequently, faecal fat energy excretion partially explain the observed reductions in body weight.

In addition to its effects on physiological measures, RE significantly reduced elevated cholesterol levels that were induced by the HFD. Although these effects were not observed by Harach et al. ${ }^{(22)}$ or Ninomiya et al. ${ }^{(19)}$, they were observed in human subjects with Orlistat ${ }^{(28-30)}$ and in animal models with other plant-based pancreatic lipase inhibitors $^{(31,32)}$. Dietary cholesterol absorption has been proposed to be associated with fat digestion; Young \& Hui ${ }^{(33)}$ have shown that minimal TAG hydrolysis is sufficient to increase cholesterol transport significantly from lipid emulsions to intestinal cells. Consequently, pancreatic lipase inhibition has been proposed to be a target against which lipid malabsorption can be triggered to control TAG and cholesterol levels ${ }^{(33)}$.

In the present study, fasting glycaemia was reduced in animals in the HFD-RE group compared with the HFD control group. Few studies have evaluated the effect of rosemary on diabetes. Anti-hyperglycaemic effects can be induced by an ethanolic RE in the alloxan diabetic rat model ${ }^{(34)}$ and by a water RE in a mouse model ${ }^{(24)}$, whereas no such effect has been observed in the diet-induced obesity mouse model with an extract that contains rosmarinic acid, carnosol and carnosic $\operatorname{acid}^{(22)}$. Based on these data, it appears that the

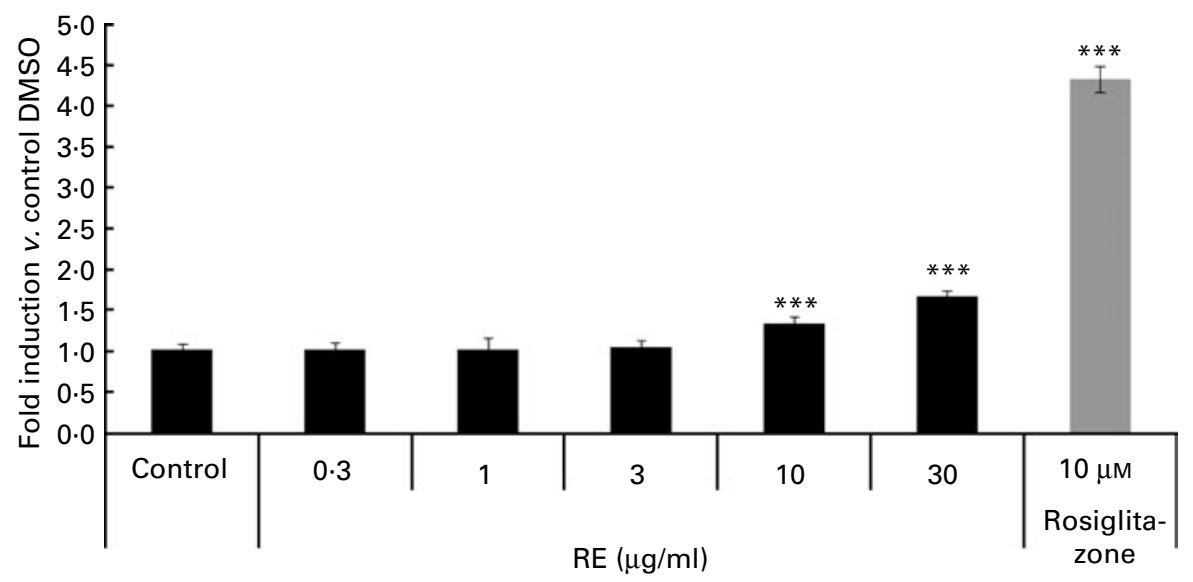

Fig. 5. Effects of rosemary extract (RE) standardised to $20 \%$ carnosic acid on PPAR- $\gamma$ activation in vitro. Values are means, with standard deviations represented by vertical bars expressed as a percentage of inhibition of three independent experiments. Mean values were significantly different from the blank control (Student's $t$ test): ${ }^{* \star} P<0.001$. DMSO, dimethyl sulfoxide. 
anti-hyperglycaemic activity and preventive effects of an extract against type 2 diabetes mellitus depend on its composition and the animal model in which it is tested.

Recently, it has been reported that the glucose-lowering effect of rosemary is attributed to PPAR- $\gamma$ activation, in which carnosic acid and carnosol were proposed be the active compounds ${ }^{(20)}$. Therefore, we examined the in vitro effects of RE on PPAR- $\gamma$ activation, hypothesising that the glucose-lowering effects are mediated through this mechanism.

In the present study on $\mathrm{C} 57 \mathrm{BL} / 6 \mathrm{~J}$ mice, we used an effective dose of RE - $500 \mathrm{mpk}$ - that contains $100 \mathrm{mpk}$ of carnosic acid. The European Food Safety Authority Panel on Food Additives has estimated the dietary exposure for adults and pre-school children (aged $1.5-4.5$ years) to carnosol plus carnosic acid to be 0.04 and $0.11 \mathrm{mpk}$, respectively ${ }^{(13)}$. Thus, considering the normal dietary exposure of carnosic acid, we used a pharmacological dose of RE.

In addition, the Panel also notes that the margin between the not observable adverse effect level of carnosol plus carnosic acid, as calculated in $90 \mathrm{~d}$ rat studies, is equivalent to $20-60 \mathrm{mpk}$, and the mean intake of carnosic acid-rich rosemary extracts is estimated to be $500-1500 \mathrm{mg} / \mathrm{d}$ in adults and $182-546 \mathrm{mg} / \mathrm{d}$ in pre-school children ${ }^{(13)}$. Therefore, future randomised clinical trials that aim to confirm the efficacy of RE in humans should consider these values to establish an effective and safe dose.

In conclusion, we have demonstrated that a carnosicstandardised RE limits weight gain and improves plasma lipid and glucose levels in a HFD mouse model. These data confirm its potential for use in preventive strategies against metabolic disorders and encourage the initiation of further studies to recapitulate the physiological activity of $\mathrm{RE}$ in human subjects.

\section{Acknowledgements}

Naturex is involved in the research/development and marketing/sales of rosemary extracts as ingredients for the food, cosmetic and nutraceutical industries. Therefore, Naturex has a commercial interest in this publication. Naturalpha was paid by Naturex to perform and report the scientific work that formed the basis of this publication. Naturalpha and Naturex declare that the data in this report represent a true and faithful representation of the work that has been performed. The financial assistance from Naturex is gratefully acknowledged. A. I. and C. R. designed the protocol. J. C. and M. R. developed the sample of RE. The study was conducted under the supervision of A. C. A. C.-B. analysed the data and reviewed the manuscript.

\section{References}

1. Baena Diez JM, del Val Garcia JL, Tomas PJ, et al. (2005) Cardiovascular disease epidemiology and risk factors in primary care. Rev Esp Cardiol 58, 367-373.

2. Anderson JW \& Konz EC (2001) Obesity and disease management: effects of weight loss on comorbid conditions. Obes Res 9, Suppl. 4, 326S-334S.
3. Czernichow S, Mennen L, Bertrais S, et al. (2002) Relationships between changes in weight and changes in cardiovascular risk factors in middle-aged French subjects: effect of dieting. Int J Obes Relat Metab Disord 26, 1138-1143.

4. Unwin N, Gan D \& Whiting D (2010) The IDF diabetes atlas: providing evidence, raising awareness and promoting action. Diabetes Res Clin Pract 87, 2-3.

5. Furukawa S, Fujita T, Shimabukuro M, et al. (2004) Increased oxidative stress in obesity and its impact on metabolic syndrome. J Clin Invest 114, 1752-1761.

6. Gregor MF \& Hotamisligil GS (2010) Inflammatory mechanisms in obesity. Annu Rev Immunol 29, 415-445.

7. Jouad H, Haloui M, Rhiouani H, et al. (2001) Ethnobotanical survey of medicinal plants used for the treatment of diabetes, cardiac and renal diseases in the North centre region of Morocco (Fez-Boulemane). J Ethnopharmacol 77, 175-182.

8. Raskin I, Ribnicky DM, Komarnytsky S, et al. (2002) Plants and human health in the twenty-first century. Trends Biotechnol 20, 522-531.

9. Balunas MJ \& Kinghorn AD (2005) Drug discovery from medicinal plants. Life Sci 78, 431-441.

10. Ye J (2008) Botanical treatments for diabetes and obesity. Endocr Metab Immune Disord Drug Targets 8, 77.

11. Panda H (2009) Cultivation of Rosmarinus officinalis. In Aromatic Plants Cultivation, Processing and Uses, pp. 22-28 (National Institute of Industrial Research, editor). New Delhi: Asia Pacific Business Press, Inc.

12. Etter SC (2004) Rosmarinus officinalis as an antioxidant. $J$ Herbs Spices Med Plants 11, 121-159.

13. Aguilar F, Autrup H, Barlow S, et al. (2008) Use of rosemary exracts as a food additive. Scientific opinion of the panel on food additives, flavourings, processing aids and materials in contact with food. EFSA J 721, 1-29.

14. Al-Sereiti MR, Abu-Amer KM \& Sen P (1999) Pharmacology of rosemary (Rosmarinus officinalis Linn.) and its therapeutic potentials. Indian J Exp Biol 37, 124-130.

15. Ibarra A, Cases J, Bily A, et al. (2010) Importance of extract standardization and in vitro/ex vivo assay selection for the evaluation of antioxidant activity of botanicals: a case study on three Rosmarinus officinalis L. extracts. J Med Food 13, 1167-1175.

16. Posadas SJ, Caz V, Largo C, et al. (2009) Protective effect of supercritical fluid rosemary extract, Rosmarinus officinalis, on antioxidants of major organs of aged rats. Exp Gerontol 44, 383-389.

17. Yu YM, Lin CH, Chan HC, et al. (2009) Carnosic acid reduces cytokine-induced adhesion molecules expression and monocyte adhesion to endothelial cells. Eur J Nutr $\mathbf{4 8}$, 101-106.

18. Mengoni ES, Vichera G, Rigano LA, et al. (2010) Suppression of COX-2, IL-1beta and TNF-alpha expression and leukocyte infiltration in inflamed skin by bioactive compounds from Rosmarinus officinalis L. Fitoterapia 82, 414-421.

19. Ninomiya K, Matsuda H, Shimoda H, et al. (2004) Carnosic acid, a new class of lipid absorption inhibitor from sage. Bioorg Med Chem Lett 14, 1943-1946.

20. Rau O, Wurglics M, Paulke A, et al. (2006) Carnosic acid and carnosol, phenolic diterpene compounds of the labiate herbs rosemary and sage, are activators of the human peroxisome proliferator-activated receptor gamma. Planta Med $\mathbf{7 2}$ $881-887$

21. Takahashi T, Tabuchi T, Tamaki Y, et al. (2009) Carnosic acid and carnosol inhibit adipocyte differentiation in mouse 3T3L1 cells through induction of phase 2 enzymes and activation of glutathione metabolism. Biochem Biophys Res Commun 382, 549-554. 
22. Harach T, Aprikian O, Monnard I, et al. (2010) Rosemary (Rosmarinus officinalis L.) leaf extract limits weight gain and liver steatosis in mice fed a high-fat diet. Planta Med 76, 566-571.

23. Wang T, Takikawa Y, Satoh T, et al. (2011) Carnosic acid prevents obesity and hepatic steatosis in ob/ob mice. Hepatol Res 41, 87-92.

24. Erenmemisoglu A, Saraymen R \& Ustun S (1997) Effect of a Rosmarinus officinalis leave extract on plasma glucose levels in normoglycaemic and diabetic mice. Pharmazie 52, 645-646.

25. Folch J, Lees M \& Stanley GH (1957) A simple method for the isolation and purification of total lipides from animal tissues. J Biol Chem 226, 497-509.

26. Surwit RS, Feinglos MN, Rodin J, et al. (1995) Differential effects of fat and sucrose on the development of obesity and diabetes in C57BL/6J and A/J mice. Metabolism 44, 645-651.

27. Black BL, Croom J, Eisen EJ, et al. (1998) Differential effects of fat and sucrose on body composition in $\mathrm{A} / \mathrm{J}$ and $\mathrm{C} 57 \mathrm{BL} / 6$ mice. Metabolism 47, 1354-1359.

28. Micic D, Ivkovic-Lazar T, Dragojevic R, et al. (1999) Orlistat, a gastrointestinal lipase inhibitor, in therapy of obesity with concomitant hyperlipidemia. Med Pregl 52, 323-333.
29. Muls E, Kolanowski J, Scheen A, et al. (2001) The effects of orlistat on weight and on serum lipids in obese patients with hypercholesterolemia: a randomized, double-blind, placebocontrolled, multicentre study. Int J Obes Relat Metab Disord 25, 1713-1721.

30. Erdmann J, Lippl F, Klose G, et al. (2004) Cholesterol lowering effect of dietary weight loss and orlistat treatmentefficacy and limitations. Aliment Pharmacol Ther 19, 1173-1179.

31. Han LK, Zheng YN, Yoshikawa M, et al. (2005) Anti-obesity effects of chikusetsusaponins isolated from Panax japonicus rhizomes. BMC Complement Altern Med 5, 9.

32. Sheng L, Qian Z, Zheng S, et al. (2006) Mechanism of hypolipidemic effect of crocin in rats: crocin inhibits pancreatic lipase. Eur J Pharmacol 543, 116-122.

33. Young SC \& Hui DY (1999) Pancreatic lipase/colipasemediated triacylglycerol hydrolysis is required for cholesterol transport from lipid emulsions to intestinal cells. Biochem J 339, 615-620.

34. Bakirel T, Bakirel U, Keles OU, et al. (2008) In vivo assessment of antidiabetic and antioxidant activities of rosemary (Rosmarinus officinalis) in alloxan-diabetic rabbits. J Ethnopharmacol 116, 64-73. 